\title{
No evidence for proteolytic venom resistance in southern African ground squirrels
}

Molly A. Phillips, Jane M. Waterman, Pg Du Plessis, Martin Smit, and Nigel C. Bennett

Abstract

Many species that interact with venomous snakes show resistances to their venoms. The family Sciuridae has several North American members that harass venomous snakes and show proteolytic resistances in their sera. We examined sera collected from an African ground squirrel (Xerus inauris) against two sympatric venomous snakes (Bitis arietans and Naja annulifera) and found no support for proteolytic resistance. Our results add to our understanding of the risks in predator defense within the family Sciuridae.

Keywords: Xerus inauris; Bitis arietans; Naja annulifera; Venom; Venom resistance; Predator-prey

Animal venoms are a complex mixture of proteins and peptides that induce many destructive physiological effects for a variety of purposes, including prey capture (Fry et al., 2008; Jansa and Voss, 2011), digestion (Thomas and Pough, 1979), and defense (Kardong, 1982). The evolution of venom in snakes is thought to be a major factor leading to the radiation of over 2500 advanced snake species (Vidal, 2002). Some animals that interact with venomous snakes have physiological resistance to venom. As a predator, the Indian grey mongoose (Herpestes edwardsii) is resistant to the haemorrhagic effects caused by the venom of many snake species (Tomihara et al., 1990). California ground squirrels (Spermophilus (Otospermophilus) beecheyi) defend against snake predation by mobbing and have resistance against the proteolytic activity of the venom from northern Pacific rattlesnakes (Crotalus oreganus) (Biardi, 2000).

The Cape ground squirrel (Xerus inauris) is a ground-dwelling sciurid that inhabits the arid regions of southern Africa (Skurski and Waterman, 2005). X. inauris, similar to S. beecheyi, approaches and mobs several venomous species of snake (Owings and Coss, 1977; Waterman, 1997; Waterman and Roth, 2007). However, it is unknown if $X$. inauris has similar proteolytic resistance to native venomous snakes. 
We focused on two species of venomous snakes that prey on rodents and live sympatrically with $X$. inauris, the puff adder (Bitis arietans) and the snouted cobra (Naja annulifera) (Broadley, 1990; Phelps, 1989; Shine et al., 2007). The venom of B. Arietans causes severe local and systemic effects to tissue including swelling, haemorrhage, and necrosis (Rippey et al., 1976; Warrell et al., 1975; Mallow et al., 2003). The venom composition of N. annulifera is similar to other members of Naja, having both neurological and cytotoxic properties (Joubert, 1976).

Our field work was conducted at S.A. Lombard Nature Reserve, located $17 \mathrm{~km}$ west of Bloemhof in the North West Province of South Africa $\left(25^{\circ} 30^{\prime} \mathrm{E}, 27^{\circ} 35^{\prime} \mathrm{S}\right)$. The reserve is classified as Kalahari grassland consisting of Cymbopogon-Themeda veld on a floodplain (Van Zyl, 1965). We live-trapped ten adult squirrels (five males and five females) from the study population using Tomahawk live traps $(15$ x 15 x 50cm; Tomahawk Live Trap Co., Tomahawk, WI, U.S.A.) between June and November 2011. We constrained trapped squirrels in a cloth bag (Koprowski, 2002) and collected $1 \mathrm{ml}$ of whole blood via the femoral or caudal arteries using 27gauge needles and capillary tubes (see Waterman, (2002) for more details on trapping and handling methods). The blood was stored in $1.5 \mathrm{ml}$ microcentifuge vials at $4^{\circ} \mathrm{C}$ overnight. We discarded the clots before centrifuging the blood sample at $2000 \mathrm{rpm}$ for $30 \mathrm{~min}$ at $4^{\circ} \mathrm{C}$ to separate any remaining erythrocytes. The remaining plasma was stored at $-4^{\circ} \mathrm{C}$ until use (Biardi et al., 2000). Venom from wild-caught B. arietans $(\mathrm{n}=3)$ and $N$. annulifera $(\mathrm{n}=2)$ were collected by the Pangea Reptile Conservations Projects CC (and immediately frozen) in the North West province of South Africa. We mixed the venom in $10 \mathrm{mg} / \mathrm{ml}$ of $20 \mathrm{mM}$ Tris- $\mathrm{HCl}+1 \mathrm{mM} \mathrm{CaCl}$, $\mathrm{pH} 8.0$ and stored at $-20^{\circ} \mathrm{C}$ at the University of Pretoria until use. 
We quantified hydrolysis of gelatin based on methods from Biardi et al. (2000) and Palmer (1993). We made a gel solution of $1.0 \%$ agarose and $0.75 \%$ gelatin (Type I, bovine skin, Sigma Chemical Co.) in $20 \mathrm{mM}$ Tris- $\mathrm{HCl}+1 \mathrm{mM} \mathrm{CaCl}_{2}$ which we poured into $140 \mathrm{~mm}$ glass petri dishes. We punched equally spaced $3 \mathrm{~mm}$ diameter wells into the gel and loaded them with $20 \mu \mathrm{l}$ of sample. Our three treatments were: (1) $5 \mu \mathrm{l}$ venom (10 mg/ml) in $15 \mu \mathrm{l}$ Tris buffer (control); (2) $5 \mu 1$ venom $+5 \mu 1$ serum $+10 \mu 1$ Tris buffer; and, (3) $5 \mu 1$ serum $+15 \mu 1$ Tris buffer (second control). We incubated the gel at $37^{\circ} \mathrm{C}$ for 24 hours and then we precipitated the unhydrolyzed gelatin in a saturated ammonium sulfate solution at $70^{\circ} \mathrm{C}$ for $10 \mathrm{~min}$. We quantified the area of lysis by averaging two measurements of the diameter across the lysis zone using calipers (Biardi et al., 2000). We replicated each treatment three times per individual for both venoms to increase precision. We randomized the order of treatments on each plate using a random number generator. We calculated means for the diameters of each treatment and compared means using ANOVA, and Tukey-Kramer HSD tests for all treatments

When exposed to B. arietans venom, the damage in the areas treated with venom and venom-serum were significantly larger than the areas treated with the serum control (Figure 1, $\left.F_{2,29}=4462.213, p<0.001\right)$. We found no significant difference in size of the lysis diameters when we compared areas treated with venom to those treated with venom-serum (Figure 1, $\left.F_{1,19}=0.1854, p=0.6719\right)$. When we examined the $N$. annulifera venom hydrolysis of the gelatin, we found the control areas (serum only) to be significantly smaller than both the venom and venom-serum areas of lysis (Figure $1, F_{2,29}=833.2601, p<0.001$ ). Similar to $B$. arietans, we found no significant difference in diameter when we compared the venom only to the venomserum treatments (Figure 1, $\mathrm{F}_{1,19}=1.2093 p=0.2860$ ). Area of lysis diameter was also significantly larger in B. arietans' venom only treatments than $N$. annulifera's illustrating the 
different proportions of cytotoxic properties in the two species' venoms (Figure 1, $\left.\mathrm{F}_{1,19}=1103.002, p<0.001\right)$.

The lack of resistance against proteolytic activity in the sera of $X$. inauris against $B$. arietans and N. annulifera venom differs from previous work from Biardi et al. (2000). They compared a North American sciurid with one sympatric and two allopatric crotalids. Their results indicated that $S$. beecheyi's sera inhibited proteolytic activity of venom from the sympatric species more effectively than two allopatric species. $X$. inauris and $S$. beecheyi are similar behaviourally in that both species approach, inspect, and harass venomous snakes that are documented predators of the species (Owings and Coss, 1977; Waterman, 1997). The risks of mobbing are mitigated in $S$. beecheyi by proteolytic resistance whereas $X$. inauris is risking death from envenomation when approaching within striking distance.

Other mammals that frequently interact with venomous snakes have venom resistance. For instance, several species of opossum (Didelphis) that prey on various pit vipers have natural resistances against their venoms (Almeida-Santos et al., 2000; Oliveira and Santori, 1999; Perez et al., 1979). Rock squirrels (Spermophilus variegatus), another North American sciurid, also have natural inhibition in their sera against rattlesnake venom's digestive and hemostatic activities (Biardi and Coss, 2010). S. variegatus is similar to S. beecheyi and X. inauris in its approach and harassment of venomous snakes (Owings et al., 2001). Unlike $S$ beecheyi (and similar to $X$. inauris) $S$. variegatus is exposed to multiple venomous species throughout its range to which they show multiple resistances (Biardi and Coss, 2010). Several mongoose species (Herpestidae) have venom resistances. The Egyptian mongoose (Herpestes ichneumon) has strong resistances against venoms from the viperid and elapid families as well as against sarafotoxins, which are unique to the Atractaspididae family (Bdolah et al., 1997). H. edwardsii 
inhibits haemorrhagic activity against 17 species' venoms (though not $B$. arietans) and has resistance to elapid postsynaptic neurotoxins (Barchan et al., 1992; Tomihara et al., 1990).

Lack of venom resistance could be due to phylogenetic constraints, as $X$. inauris' ecology and behaviour are similar to other resistant sciurids. Two of the three genera in Xerini (Xerus, Atlantoxerus) are endemic to Africa whereas North American squirrels belong in the tribe Marmotini (Herron et al., 2005; Mercer and Roth, 2003). Further investigation into venom resistance within the two clades would need to be conducted to understand the extent of proteolytic venom resistance in sciurids.

In addition, $X$. inauris has a more complex snake predator community than other ground squirrels. These diffused evolutionary pressures could hinder the evolution of specialized resistance against any single toxin type or species of snake (Gomulkiewicz et al., 2000; Thompson, 1994). Venoms from both snake species tested are complex and usually contain multiple toxin types. B. arietans' venom includes coagulants, haemorrhagins and neurotoxins (Broadley, 1990; Mallow et al., 2003). N. annulifera, like other members of the genus Naja, has a potent neurotoxin in its venom (Joubert, 1976). X. inauris may have resistance to other types of toxins in the venoms we tested. However, they would still need to minimize the tissue destruction that follows envenomation from both species in order to maintain competitiveness against conspecifics and avoid predation (Biardi et al., 2005). Research on how ground squirrels respond to venom toxins physiologically helps clarify the risks to squirrels in snake and squirrel interactions (Biardi and Coss 2010). The lack of proteolytic resistance in X. inauris increases the risk of mobbing venomous snakes. Future research could focus on potential reasons for the occurrence of mobbing behaviours despite the risk of envenomation. 


\section{References}

Almeida-Santos, S.M., Antoniazzi, M.M., Sant'Anna, O.A., Jared, C., 2000. Predation by the opossum Didelphis marsupialis on the rattlesnake Crotalus durissus. Curr. Herp. 19, 1-9.

Barchan, D., Kachalsky, S., Neumann, D., Vogel, Z., Ovadia, M., Kochva, E., Fuchs, S., 1992. How the mongoose can fight the snake: the binding site of the mongoose acetylcholine receptor. Proc. Natl. Acad. Sci. 89, 7717-7721.

Bdolah, A., Kochva, E., Ovadia, M., Kinamon, S., Wollberg, Z., 1997. Resistance of the Egyptian mongoose to sarafotoxins. Toxicon. 35, 1251-1261.

Biardi, J.E., Coss, R.G., Smith, D.G., 2000. California ground squirrel (Spermophilus beecheyi) blood sera inhibits crotalid venom proteolytic activity. Toxicon. 38, 713-721.

Biardi, J.E., Chien, D.C., Coss, R.G., 2005. California ground squirrel (Spermophilus beecheyi) defenses against rattlesnake venom digestive and hemostatic toxins. J Chem. Ecol. 31, 25012510 .

Biardi, J.E., Coss, R.G., 2010. Rock squirrel (Spermophilus variegatus) blood sera affects proteolytic and hemolytic activities of rattlesnake venoms. Toxicon. 57, 323-331.

Broadley, D.G., 1990. FitzSimons' snakes of southern Africa. Jonathoan Ball. Johannesburg, South Africa, pp. 387.

Fry, B.G., Wroe, S., Teeuwisse, W., van Osch, M.J.P., Moreno, K., Ingle, J., McHenry, C., Ferrara, T., Clausen, P., Scheib, H., Winter, L., Griesman, L., Roelants, K., Krishnasamy, K., Kochva, E., Kwok, H.F., Scanlon, D., Karas, J., Citron, D.M., Goldstein, E.J.C., Mcnaughtan, J.E., Norman, J.A., 2009. A central role for venom in predation by Varanus komodoensis (Komodo dragon) and the extinct giant Varanus (Megalania) priscus. P. Natl. Acad. Sci. USA. 106, 8969-8974.

Gomulkiewicz, R., Thompson, J.N., Holt, R.D., Nuismer, S.L., Hochberg, M.E., 2000. Hot spots, cold spots, and the geographic mosaic theory of coevolution. Am. Nat. 156, 156-174.

Herron, M.D., Waterman, J.M., Parkinson, C.L., 2005. Phylogeny and historical biogeography of African ground squirrels: the role of climate change in the evolution of Xerus. Mol. Ecol. 14, 2273-2788.

Jansa, S.A., Voss, R.S., 2011. Adaptive evolution of the venom-targeted vWF protein in opossums that eat pitvipers. Plos. 6.

Joubert, F.J., 1976. Snake venom toxins: The amino acid sequence of three toxins (CM-2e, CM4a and CM-7) from Naja haje annulifera (Egyptian Cobra) venom. H-S. Z. Physiol. Chem. 357 , 1735-1750. 
Kardong, K.V., 1982. The evolution of the venom apparatus in snakes from colubrids to viperids \& elapids. Mem. Inst. Butantan. 46, 105-118.

Koprowski, J.L., 2002. Handling tree squirrels with a safe and efficient restraint. Wildl. Soc. Bull. 30, 101-103.

Mallow, D., Ludwig, D., Nilson, G., 2003. True vipers: natural history and toxinology of old world vipers. Krieger Publishing. Co. Melbourne, FL, pp. 60-71.

Mercer, J.M., Roth, V.L., 2003. The effects of Cenozoic global change on squirrel phylogeny. Science. 299, 1568-1572.

Oliveira, M.E., Santori, R.T., 1999, Predatory behavior of the opossum Didelphis albiventris on the pitviper Bothrops jararaca. Stud. Neotrop. Fauna. Environm. 34, 72-75.

Owings, D.H., Coss, R.G., 1977. Snake mobbing by California ground squirrels: adaptive variation and ontogeny. Behaviour. 62, 50-69.

Owings, D.H., Coss, R.G., McKernon, D., Rowe, M.P., Arrowood, P.C., 2001. Snake-directed antipredator behavior of rock squirrels (Spermophilus variegatus): population differences and snake-species discrimination. Behaviour. 138, 575-595.

Palmer, M.A., 1993. A gelatin test to detect activity and stability of proteases produced by Dichelobacter (bacteroides) nodosus. Vet. Microbiol. 36, 113-122.

Perez, J.C., Pichyangkul, S., Garcia, V.E., 1979. The resistance of three species of warm-blooded animals to western diamondback rattlesnake (Crotalus atrox) venom. Toxicon. 17, 601-607.

Phelps, T., 1989. Poisonous snakes. $2^{\text {nd }}$ edition. Blandford Press. Poole, Dorset, pp. 156.

Rippey, J.J., Rippey, E., Branch, W.R., 1976. A survey of snakebite in the Johannesburg area. S. Afr. Med. J. 50, 1872-1876.

Shine, R., Branch, W.R., Webb, J.K., Harlow, P.S., Shine, T., Keogh, J.S., 2007. Ecology of cobras from southern Africa. J. Zool. 272, 183-193.

Skurski, D.A., Waterman, J.M., 2005. Xerus inauris. Mamm. Species. 781, 1-4.

Thomas, R.G., Pough, F.H., 1979. The effect of rattlesnake venom on digestion of prey. Toxicon. 17, 221-228.

Thompson, J.N., 1994. The Coevolutionary Process. University of Chicago Press, Chicago.

Tomihara, Y., Yonaha, K., Nozaki, M., Yoshita, C., 1990. Neutralization of hemorrhagic snake venoms by sera of Trimesurus flavoviridis (Habu), Herpestes edwardsii (mongoose) and Dinodon semicarinatus (Akamata). Toxicon. 28, 989-991. 
Unck, C.E., Waterman, J.M., Verburgt, L., Bateman, P.W., 2009. Quantity versus quality: how does level of predation threat affect Cape ground squirrel vigilance? Anim. Behav. 78, 625-632.

Van Zyl, J.H.M., 1965. The vegetation of the S.A. Lombard Nature Reserve and its utilization by certain antelope. Afr. Zool. 1, 55-71.

Vidal, N., 2002. Colubroid systematics: evidence for an early appearance of the venom apparatus followed by extensive evolutionary tinkering. J. Toxicol. Toxin. Rev. 21, 21-41.

Warrell, D.A., Ormerod, L.D., McD Davidson, N., 1975. Bites by puff-adder (Bitis arietans) in Nigeria, and value of antivenom. Brit. Med. J. 4, 697-700.

Waterman, J.M., 1997. Why do male Cape ground squirrels live in groups? Anim. Behav. 53, 809-817.

Waterman, J.M., 2002. Delayed maturity, group fission and the limits of group size in female Cape ground squirrels (Sciuridae: Xerus inauris). J. Zool., Lond. 256, 113-120.

Waterman, J.M., Roth, J.D., 2007. Interspecific associations of Cape ground squirrels with two mongoose species: benefit or cost? Behav. Ecol. Sociobiol. 61, 1675-1683. 


\section{List of Figures:}

Fig. 1. Diameter of area of gelantinase activity caused by pooled venom of B. arietans (dark gray) and $N$. annulifera (light gray). Mean values with \pm standard errors are shown for each of the three treatments, venom alone, venom with the sera of $X$. inauris and the control. Comparisons for all pairs using Tukey-Kramer HSD shown above each treatment. 


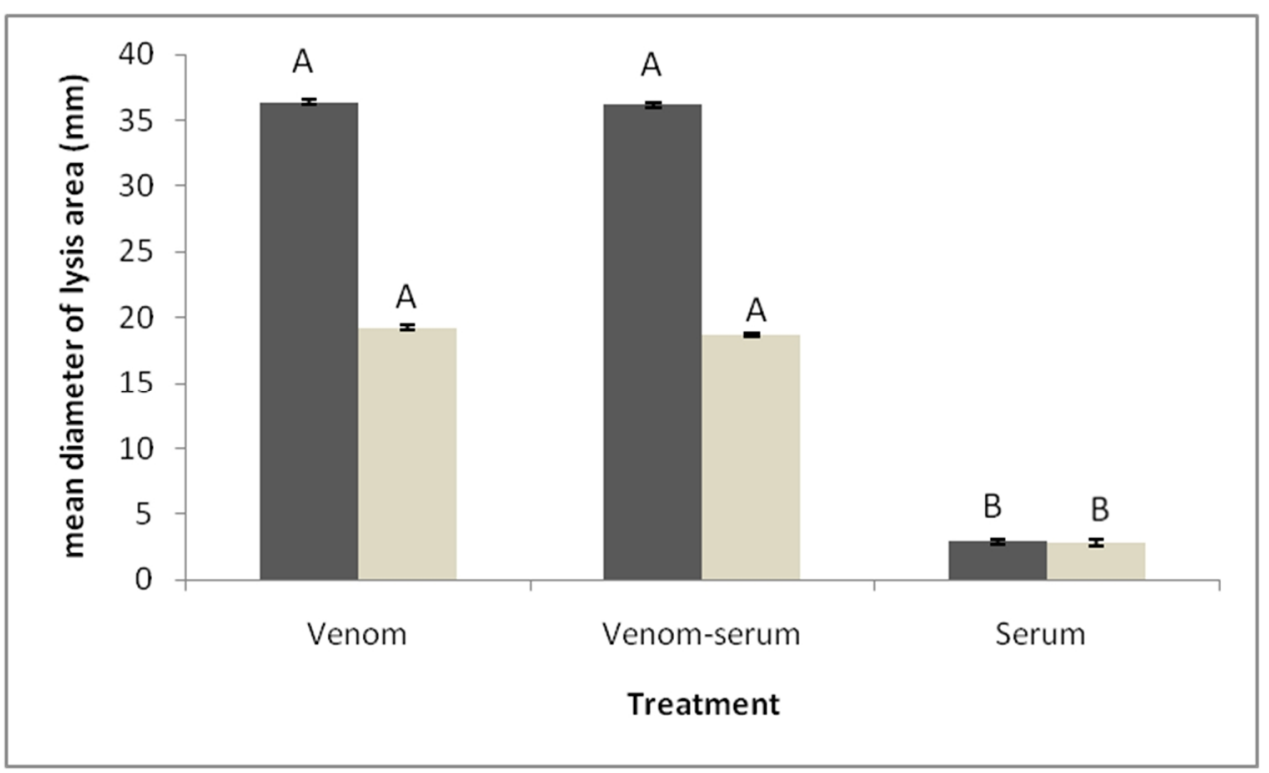

